\title{
Formação para as manipuladoras de alimentos da cozinha comunitária de Salgueiro-PE
}

\author{
Autores: Vanúsia Medeiros Silva ${ }^{1}$; Ana Cláudia Siqueira Silva ${ }^{1}$; Liliane Dária Félix ${ }^{1}$; \\ Paulo Garcez Leães ${ }^{2}$; Cristiane Ayala de Oliveira ${ }^{3}$ \\ 1- Graduanda do Curso de Tecnologia em Alimentos, IF Sertão- PE - Campus Salgueiro. \\ 2- Pedagogo, IF Sertão- PE - Campus Salgueiro. \\ 3- Docente do Curso Superior de Tecnologia em Alimentos- Orientadora do Trabalho. cristiane.ayala@ifsertao-pe.edu.br
}

\section{Introdução}

A alimentação e nutrição adequadas são requisitos essenciais para o crescimento e o desenvolvimento de todas as crianças. Mais do que isso, são direitos humanos fundamentais, pois representam a base da própria vida. Alimentar-se corretamente é um dos principais fatores para o crescimento e desenvolvimento saudáveis, portanto uma boa alimentação é a melhor forma para prevenir e combater as doenças, melhorando assim a qualidade de vida. As boas práticas (BP) são definidas como regras ou princípios básicos para o manuseio higiênico dos alimentos, adotados com a finalidade de controlar, prevenir, eliminar ou reduzir a contaminação física, química ou biológica, desde a matéria-prima até o produto final, assegurando não só a oferta de alimentos adequados ao consumo humano, mas, principalmente, a saúde do consumidor (BRASIL, 2004). O objetivo deste trabalho foi qualificar as manipuladoras e demais responsáveis pela produção da alimentação através de cursos teóricos e práticos, ministrados pela equipe do IF Sertão Pernambucano/campus Salgueiro.

\section{Relato de Experiência}

Tratou-se um estudo descritivo, de natureza qualitativa, realizado em campo, a definição do modelo do curso considerou o desenvolvimento de um trabalho integrado e interinstitucional, já estabelecido no projeto, que envolveu a Associação das Mulheres de Salgueiro (AMUSA) localizada no bairro COHAB no município de Salgueiro - PE e Instituto Federal de Educação, Ciência e Tecnologia do Sertão Pernambucano - IF Sertão - PE/ Campus Salgueiro. Sendo assim, teve-se como prioridade uma construção coletiva, através de reuniões de consenso para elaboração da proposta do curso. 


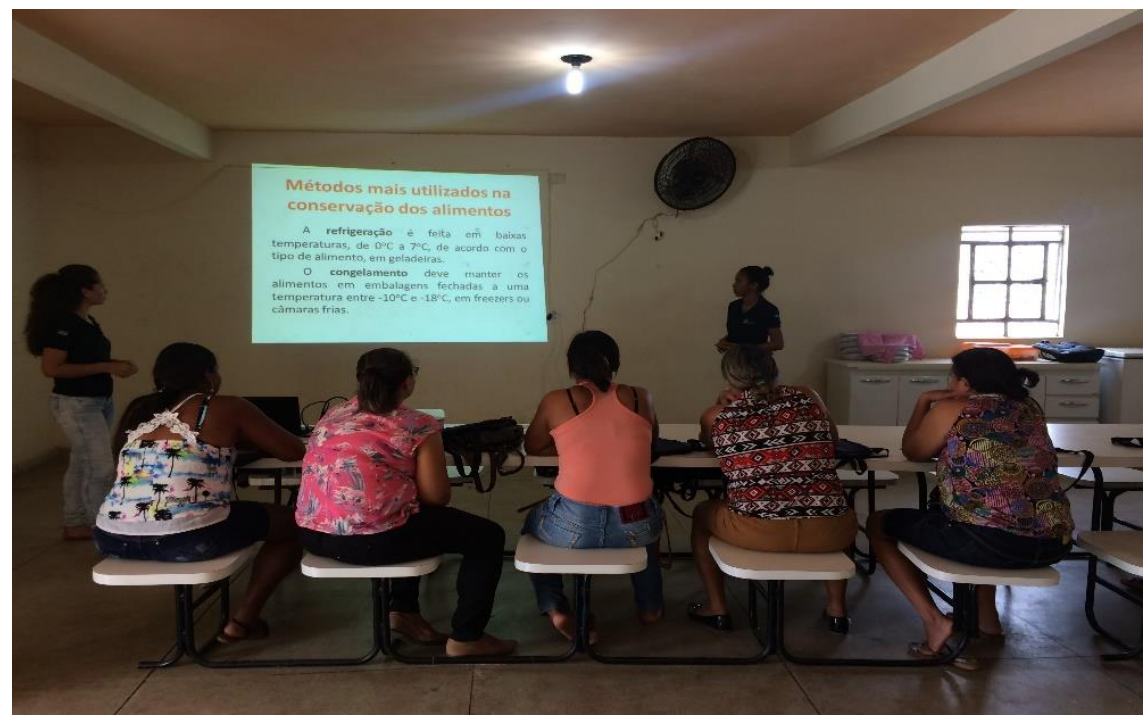

Figura 1: Capacitação das manipuladoras

Diante disso foram considerados três momentos: sondagem de conteúdos e metodologias junto às merendeiras; desenvolvimento, incluindo o planejamento do curso, sua organização e realização; e avaliação final do curso pelas manipuladoras. Buscou-se uma abordagem inserida no contexto cultural, diante disso buscou-se uma maior atuação das manipuladoras no processo de aprendizagem e primou-se pela intensa relação entre os envolvidos, buscando no próprio local onde preparam os alimentos para o desenvolvimento das atividades. As manipuladoras tiveram noções de higiene de alimentos, DTA's, armazenamento adequado de alimentos, dentre outros tópicos importantes para a manutenção de uma UAN de forma adequada, primando por segurança e qualidade.

\section{Considerações}

A participação no curso contribuiu para com a formação e o desenvolvimento de saberes e competências na área de segurança dos alimentos, assim, espera-se que com este trabalho tenha-se a possibilidade melhorar a qualidade das refeições produzidas para os usuários do serviço, como também contribuir para a formação acadêmica da aluna-bolsista.

\section{Referências Bibliográficas}

BRASIL. Ministério da Saúde do Brasil. Política Nacional de Alimentação e Nutrição. Disponível em: <http://www.saude.gov.br/sba〉. Acesso em: 12 set. 2017.

BRASIL. Ministério da Saúde. Agência Nacional de Vigilância Sanitária. Legislação. Resoluções. Resolução no 216, de 15 de setembro de 2004: dispõe sobre o Regulamento Técnico de Boas Práticas para Serviços de Alimentação.Brasília: Diário Oficial da União; 16 setembro 2004. Seção I, p. 24-27. 